\title{
Latent toxoplasmosis and vitamin D concentration in humans: three observational studies
}

\author{
Šárka Kaňková $^{1,2}$, Marie Bičíková ${ }^{3}$, Ludmila Máčová ${ }^{3}, J^{2 a n a}$ Hlaváčová ${ }^{1}$, Kateřina Sýkorová ${ }^{1}$, Dobroslava Jandová ${ }^{4}$ \\ and Jaroslav Flegr ${ }^{1,2}$
}

\author{
${ }^{1}$ Department of Philosophy and History of Science, Faculty of Science, Charles University, Prague, Czech Republic; \\ ${ }^{2}$ Applied Neurosciences and Brain Imaging, National Institute of Mental Health, Klecany, Czech Republic; \\ ${ }^{3}$ Institute of Endocrinology, Prague, Czech Republic; \\ ${ }^{4}$ Third Faculty of Medicine of Charles University, Prague, Czech Republic
}

\begin{abstract}
Numerous recent studies show that vitamin D deficiency potentiates various chronic physical and psychiatric disorders and diseases. It has been shown that a similar range of disorders is also associated with latent infection with Toxoplasma gondii (Nicolle et Manceaux, 1908). For instance, among cancer, diabetes and schizophrenia patients, we find a higher prevalence of both toxoplasmosis and vitamin D deficiency. Theoretically, therefore, vitamin D deficiency could be the missing link between toxoplasmosis and these disorders. We tested this hypothesis by searching for decreased vitamin D levels in the serum of subjects infected with $T$. gondii (furthermore called Toxoplasma-infected subjects) in two cross-sectional and one case-control study. Results of the first cross-sectional study $(\mathrm{N}=72)$ suggest that Toxoplasma-infected neurasthenic patients have non-significantly lower levels of calcidiol than Toxoplasma-free patients (study A: $\mathrm{P}=0.26$ in women, $\mathrm{P}=0.68$ in men). However, two other studies (study $\mathrm{B}: \mathrm{N}=400 ;$ study $\mathrm{C}: \mathrm{N}=191$ ) showed a non-significantly higher concentration of vitamin D in Toxoplasma-infected subjects than in Toxoplasma-free subjects both in men (study $\mathrm{B}: \mathrm{P}=0.70$, study $\mathrm{C}: \mathrm{P}=0.55$ ) and in women (study $\mathrm{B}: \mathrm{P}=0.64$, study $\mathrm{C}: \mathrm{P}=0.12$ ). Taken together, our preliminary results thus do not support the hypothesis that toxoplasmosis could be associated with vitamin $\mathrm{D}$ decrease.
\end{abstract}

Keywords: Toxoplasma gondii, calcidiol, depression, mental disorders, schizophrenia.

Toxoplasma gondii (Nicolle et Manceaux, 1908) is one of the most widespread parasitic protist in humans in developed countries. The prevalence of toxoplasmosis in human populations varies from 20 to $80 \%$ depending on various environmental and sociological factors, such as hygiene conditions and cooking habits. The main sources of infection are food or water contaminated by oocysts from feline faeces and the consumption of raw or undercooked food containing tissue cysts of the parasite (Tenter et al. 2000). Recently, new routes of transmission of $T$. gondii in humans, namely sexual intercourse (Flegr et al. 2014a) and oral sex (Kaňková et al. 2020), have been proposed. Indeed, Hlaváčová et al. (2020) showed that an infected sexual partner could be a new risk factor for women.

Toxoplasma gondii can actively enter any nucleated cell. It spreads through the host body with infected mobile cells, such as dendritic cells and monocytes. Using this Trojan horse strategy, it can enter immune privileged organs, the testes, eyes and the brain. In these organs, it infects various cell types, including neurons, Purkinje cells, and microglial cells (Da Silva and Langoni 2009). Slowly dividing bradyzoites in tissue cysts, the latent form of $T$. gondii, remain in the body for the rest of host's life and probably elicit no inflammatory response.

Vitamin D2 (ergocalciferol) and vitamin D3 (cholecalciferol) are the two main physiologically relevant forms of vitamin D. Vitamin D2 comes from the yeast and plant sterol. Vitamin D3 is formed in the subcutaneous tissue from 7-dehydrocholesterol after exposure to the UV-B component of solar radiation. In the liver, vitamins D2 and D3 undergo hydroxylation and soon after appear in the circulation as calcidiol, also known as 25 -hydroxyvitamin D (abbreviated 25[OH]D) (Institute of Medicine [US] Standing Committee on the Scientific Evaluation of Dietary Reference Intakes 1997). Circulating calcidiol concentration is a good reflection of the cumulative effects of sunlight exposure and dietary intake of vitamin D (Haddad and Hahn 1973, Lund and Sørensen 1979). The half-lives of calcidiol are generally reported to be more or less constant with a range of 10 to 40 days, but are highly dependent on the start level of calcidiol, sex and the vitamin D receptor marker rs2228570 (Datta et al. 2017). 
Vitamin D is known to play an important role in bone tissue metabolism (Ryan et al. 2013, Anderson 2017). However, it has been demonstrated that vitamin D deficiency is associated with various neurodegenerative diseases such as autism, depression, multiple sclerosis, Alzheimer's disease, Parkinson's disease, etc. (Eyles et al. 2013, Ali et al. 2018). Lack of vitamin D has been also associated with fertility problems such as polycystic ovarian dysfunction, endometriosis, uterine fibroids, abnormal sperm function and reduced in vitro fertilisation success (Lerchbaum and Obermayer-Pietsch 2012). Numerous epidemiological and observational studies have reported that higher serum calcidiol D levels are associated with lower incidences of various cancers (Feskanich et al. 2004, Tworoger et al. 2007, Abbas et al. 2008, Garland et al. 2009). Other studies, in different population groups, have found a correlation between low levels of calcidiol and an increased risk of type 1 diabetes (Bin-Abbas et al. 2011, Chakhtoura and Azar 2013, De Oliveira et al. 2018). Vitamin D also plays an important role in the cardiovascular system. Low serum levels of calcidiol are closely related to the incidence of cardiovascular diseases in general (Lavie et al. 2013), and possibly also specifically to hypertension (Ferder et al. 2013).

Toxoplasmosis is associated with specific neurological and neuropsychiatric symptoms (Flegr 2015a). In particular, it has been found that subjects infected with $T$. gondii (furthermore called Toxoplasma-infected subjects) have higher incidences of depression (Hsu et al. 2014), anxiety (Markovitz et al. 2015), and are at a higher risk of suicide (Arling et al. 2009, Pedersen et al. 2012), schizophrenia (Torrey and Yolken 2003, Torrey et al. 2012, Flegr 2015b, Sutterland et al. 2015), obsessive-compulsive disorder, autism, attention deficit hyperactivity disorder, and bipolar disorder (Flegr et al. 2014c, Flegr and Escudero 2016, Flegr and Horacek 2018). Seroprevalence of toxoplasmosis correlates with various disease burdens, for instance the disease burden of cardiovascular and endocrine disorders (Flegr et al. 2014b, Kaňková et al. 2015a). A higher prevalence of toxoplasmosis was observed in patients with nasopharyngeal carcinoma and rectal cancer (Yuan et al. 2007), as well as leukaemia and prostate cancer (Flegr et al. 2014b). Several studies have found an association between toxoplasmosis and infertility (Zhou et al. 2002, Babu et al. 2007, Kaňková et al. 2015b).

Similarity between the range of neuropsychiatric disorders and chronic physical diseases associated with Toxoplasma infection and with vitamin D insufficiency (Schneider et al. 2000, Cantor-Graae and Selten 2005, Bresnahan et al. 2007, Davis et al. 2016), as well as both in vivo and in vitro effects of vitamin $\mathrm{D}$ on the proliferation of $T$. gondii (Ghaffarifar et al. 2010), suggests that a hypothetical toxoplasmosis-associated decrease of vitamin $\mathrm{D}$ may play a role in the observed association between toxoplasmosis and the aforementioned range of diseases and disorders. Toxoplasma gondii might lower the concentration of vitamin $\mathrm{D}$ to impede the activity of host defence mechanisms. Increased incidences of various physical and neuropsychiatric disorders could then be a side-effect of this decrease in vi- tamin D levels. Alternatively, it is possible that people with pre-existing lower levels of vitamin D are more likely to both suffer from certain physical and mental disorders (such as schizophrenia) and to acquire a Toxoplasma infection.

Recently, two studies presented the results related to vitamin D and Toxoplasma infection in humans. Kashan et al (2019) showed that anti-T. gondii IgG antibody was positive in $17 \%$ of the normal vitamin $\mathrm{D}$ group and $28 \%$ in vitamin D deficient group. Tayeb et al. (2019) observed higher vitamin D deficiency among young women (from 15 to 25 years) with acute toxoplasmosis. However, both mentioned studies have several limitations, such as atypical sample and statistical analyses without enrolled age as a covariate.

In the present studies, we tested a (preregistered) hypothesis that Toxoplasma-infected subjects have lower vitamin D levels in blood serum than Toxoplasma-free subjects do by measuring the concentration of vitamin $\mathrm{D}$ in the serum of subjects from three independent populations tested for Toxoplasma infection.

\section{MATERIALS AND METHODS}

\section{Subjects}

\section{Study A. Cross-sectional study performed on a cohort of 72 neurasthenic patients}

The study was designed as a cross-sectional study in 2017. The dataset covered 72 clients of the Jeseník health resort. The subjects had various mental health problems, mostly anxiety and depression, and corresponding psychiatric diagnoses, usually F 41.2, F 33.1 and F 32.1. As part of the intake examination, they were blood-sampled and their sera were assayed for calcidiol concentrations. All participants gave their informed consent and the serological examination of anonymised sera for the purpose of the present study was approved by the Ethics Committee of the Institute of Endocrinology (2017).

\section{Study B (preregistered study). Case-control study performed on 400 subfertile subjects}

The data were collected at the Centre of Assisted Reproduction of the Department of Obstetrics and Gynaecology of the First Faculty of Medicine and General University Hospital in Prague (CAR) in 2016-2018. The CAR was visited by couples with fertility problems. All couples were thoroughly examined for possible causes of their infertility. During a routine examination, their blood was also collected for serological testing for toxoplasmosis. In this study, we included 400 subjects who all gave their informed consent. The sample consisted of 200 Toxoplasma-positive subjects (100 men and 100 women) and 200 Toxoplasma-negative control subjects (100 men and 100 women) matched by age and date of blood collection.

This study was approved by the Ethics Committee of the General University Hospital in Prague (No. 384/16; 92/17) and by the Ethics Committee of the Faculty of Science, Charles University in Prague (No. 2015/29) and preregistered separately for women (DOI 10.17605/OSF.IO/DE2XU) and men (DOI 10.17605/ OSF.IO/3M4Q6) in the Open Science Framework. We analysed the effects of toxoplasmosis on calcidiol levels in both men and women, as was preregistered. Hypotheses focused on specific 


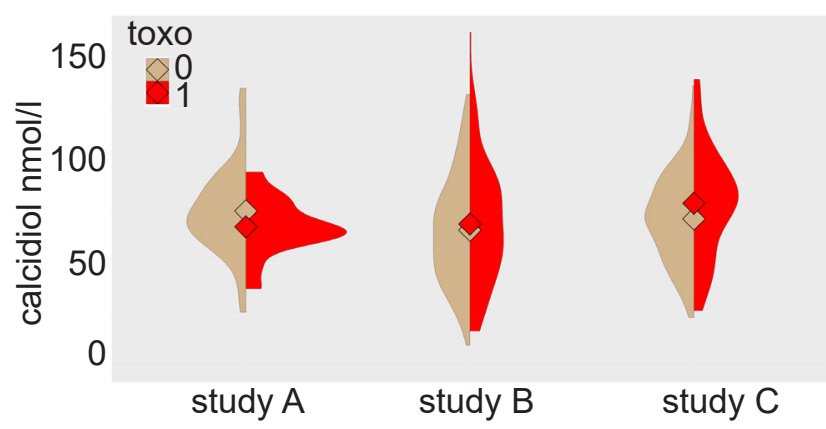

Fig. 1. Difference in calcidiol concentrations between Toxoplasmafree $(0)$ and Toxoplasma-infected (1) subjects. A- a cross-sectional study of clients of the Jeseník health resort; B - case-control study of subfertile subjects; $\mathrm{C}$ - a cross-sectional study performed on a cohort drawn from the general population. The figure shows the means and the distribution computed as the kernel probability density.

neurologic and neuropsychiatric symptoms mentioned in preregistrations will be the subject of a separate study.

Study C. (confirmation study). Cross-sectional study performed on 191 members of the general public

Serological samples were collected during behavioural experiments performed at the Faculty of Science, Charles University in Prague, over several days in September and October 2018. Participants were recruited mostly via the Facebook group 'Lab Bunnies', an 18,000-strong group of Czech and Slovak nationals willing to participate in experiments designed and performed by evolutionary psychologists (www.facebook.com/pokusnikralici).

Invitation to the study was also distributed via other Facebook groups and leaflets handed out on the street. Testing for calcidiol concentration and toxoplasmosis was offered as a reward for participation in the study. For this study, we gathered data from 203 subjects. A total of 191 subjects were willing to participate in blood collection for serological testing. The project was approved by the Institutional Review Board of Charles University, Faculty of Science (No. 2018/30).

The authors assert that all procedures on which this work is based comply with the ethical standards of the relevant national and institutional committees on human experimentation and with the Helsinki Declaration of 1975 as revised in 2008 .

\section{Laboratory assessment}

All blood serum samples were frozen and stored in a freezer. Testing for toxoplasmosis was performed in the National Reference Laboratory for Toxoplasmosis at the National Institute of Public Health in Prague. Calcidiol levels were assayed at the Institute of Endocrinology in Prague.

\section{Immunological tests for toxoplasmosis}

The complement-fixation test (CFT), which determines the overall level of $\operatorname{IgM}$ and $\operatorname{IgG}$ antibodies of particular specificity and enzyme-linked immunosorbent assay (ELISA) (IgG ELISA: SEVAC, Prague, IgM ELISA: TestLine, Brno) were used to detect toxoplasmosis status. By using both IgM and IgG ELISA, we could discriminate between the acute and latent stage of the infection. Latent toxoplasmosis was defined as a CFT titre of $1: 4$ and more in conjunction with index of positivity (IP) $>1.2$ for IgG ELISA and IP $<1.0$ for IgM ELISA (Kodym et al. 2007). Subjects

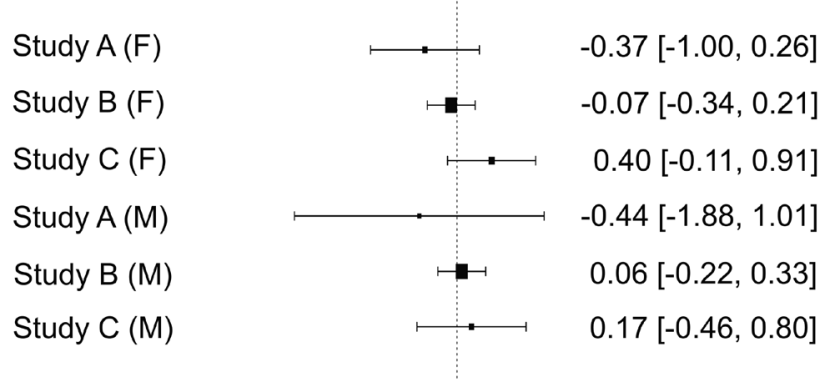

RE Model

$0.02[-0.15,0.19]$

\begin{tabular}{ll|lll}
\hline-2 & -1 & 0 & 1 & 2
\end{tabular}

Fig. 2. Forest plot showing effect sizes and $95 \%$ confidence intervals for individual studies $(\mathrm{A}-\mathrm{C})$ for male $(\mathrm{M})$ and female $(\mathrm{F})$.

with ambiguous results of serological testing, mostly those with conflicting results of IgG ELISA and CFT test, were excluded from the analysis. In our three populations, we found no subjects with acute toxoplasmosis (high IgM subjects).

\section{Calcidiol testing}

To measure the concentration of calcidiol, we used High Performance Liquid Chromatography with UV/VIS detection (ClinRep ${ }^{\circledR}$ Complete Kit for 25-OH-Vitamin D2/D3, produced by RECIPE Chemicals + Instruments GmbH, Munich, Germany) (Enko et al. 2014). For system check, calibration and internal quality control certified materials traceable to NIST standard SRM 972a were used. The kit is certified for in vitro diagnostic use (IVDD, 98/79/EC).

It must be noted that recommendations for reference values for calcidiol concentration in the serum vary. Manufacturers of the calcidiol kit which uses chromatography are among those who use a reference range of 75-250 nmol/1 (Vierucci et al. 2014, Bizzaro et al. 2017). Based on a number of meta-analyses, a number of European countries and the U.S.A. recommend that the bottom of this range be used as the lower limit of the normal range (Papadimitriou 2017). We have therefore used reference value of $75 \mathrm{nmol} / 1$ to define low calcidiol levels in our subjects.

\section{Statistics}

We used the Statistica 10.0 program and Jamovi 1.2.22.0. for all statistical testing. To investigate the main hypothesis, we performed a t-test with toxoplasmosis as an independent binary (positive/negative) variable and calcidiol levels as a continuous dependent variable in study B (with age-matched controls). In studies A and C, we used the ANCOVA with toxoplasmosis as a binary independent variable, calcidiol levels as a continuous dependent variable, and participant age as a continuous predictor. We also explored whether among the Toxoplasma-positive subjects, there are more individuals whose calcidiol levels in the serum are under the lower reference value $(75 \mathrm{nmol} / \mathrm{l}$, the usual threshold value in Europe) than among Toxoplasma-negative subjects. To investigate this hypothesis, we conducted logistic regressions for the binary variable calcidiol level under the lower reference value (yes/no), and with binary variable toxoplasmosis (positive/negative) as predictor. All analyses were performed separately for men and women in each study. 
In the statistical analyses, we slightly deviated from the preregistration. Because the effect of latent toxoplasmosis on calcidiol levels turned out to be the opposite of what we expected in the preregistration, we applied a two-sided instead of a one-sided t-test. Everything else was carried out according to the preregistration.

To summarise these studies, we present the forest plot and we performed a meta-analysis using the MAJOR module of the Jamovi 1.2.22.0 program (Viechtbauer 2010). We compared the results of the influence of latent toxoplasmosis on calcidiol concentration for both men and women with one random-effects model.

The final raw data set is available at figshare https://doi. org/10.6084/m9.figshare.9828026.v1.

\section{RESULTS}

\section{Study A. A cross-sectional study of clients of the Jeseník health resort}

The sample consisted of 72 subjects, 64 women (age $=54.2, \mathrm{SD}=10.13)$ and 8 men $(\mathrm{age}=52.6, \mathrm{SD}=8.42)$. Three men and 12 women tested positive for Toxoplasma gondii. In the sample as a whole, calcidiol concentrations approximately followed the normal distribution. We have therefore compared the effect of toxoplasmosis on calcidiol concentrations using the ANCOVA, but both the nonparametric Spearman test and partial Kendall correlation test with age as a covariate yielded qualitatively the same results (not shown).

Figure 1A suggests that Toxoplasma-infected subjects had lower calcidiol concentrations than Toxoplasma-free subjects, but this effect was non-significant in both the women $\left(\mathrm{F}_{1,61}=1.28, \mathrm{P}=0.263\right.$, eta $\left.^{2}=0.02\right)$ and the men $\left(\mathrm{F}_{1,5}\right.$ $=0.20, \mathrm{P}=0.675$ eta $\left.^{2}=0.04\right)$. Calcidiol levels in 3 Toxoplasma-positive $\left(\right.$ mean $\left.=74.2 \mathrm{nmol} / 1 ; \mathrm{CI}_{95}=34.9-114\right)$ and 5 Toxoplasma-negative men $\left(\right.$ mean $=88.2 \mathrm{nmol} / 1 ; \mathrm{CI}_{95}=$ 57.7-119) were similar. Analogously, calcidiol levels were almost the same in the 12 Toxoplasma-positive (mean = $66.2 \mathrm{nmol} / \mathrm{l} ; \mathrm{CI}_{95}=57.8-74.6$ ) and the 52 Toxoplasma-negative women $\left(\right.$ mean $\left.=72.8 \mathrm{nmol} / 1 ; \mathrm{CI}_{95}=67.7-77.9\right)$. Age had a non-significant effect in this model in both men $(\mathrm{P}=$ $0.60)$ and women $(\mathrm{P}=0.50)$.

Latent toxoplasmosis had no effect on lowering calcidiol levels below the lower reference value $(75 \mathrm{nmol} / \mathrm{l})$. The results of logistic regression were non-significant in both women $\left(\mathrm{P}=0.33, \mathrm{OR}=2.03, \mathrm{CI}_{95}=0.49-8.40\right)$ and men $(\mathrm{P}$ $\left.=0.47, \mathrm{OR}=3.0, \mathrm{CI}_{95}=0.15-59.89\right)$.

\section{Study B. (preregistered study). Case-control study on subfertile subjects}

In this sample of 200 men and 200 women, the average age was 35.8 years $(\mathrm{SD}=4.64)$ for men and 33.7 years $(\mathrm{SD}=3.86)$ for women. Our results showed no significant influence of latent toxoplasmosis on calcidiol levels in either women $\left(\mathrm{t}_{198}=-0.47, \mathrm{P}=0.64\right)$ or men $\left(\mathrm{t}_{198}=0.38, \mathrm{P}=\right.$ 0.70 ; Fig. 1B.). Because the effect of latent toxoplasmosis on calcidiol levels was the opposite of what we expected in the preregistration, we performed a two-sided test. We found that calcidiol levels were similar in 100 Toxoplasma-positive $\left(\right.$ mean $=65.0 \mathrm{nmol} / 1 ; \mathrm{CI}_{95}=59.2$
70.7) and 100 Toxoplasma-negative men (mean $=63.4$ $\left.\mathrm{nmol} / \mathrm{l} ; \mathrm{CI}_{95}=57.8-69.1\right)$ as well as in 100 Toxoplasmapositive $\left(\right.$ mean $\left.=71.7 \mathrm{nmol} / 1 ; \mathrm{CI}_{95}=66.6-76.9\right)$ and 100 Toxoplasma-negative women $\left(\right.$ mean $=73.4 \mathrm{nmol} / 1 ; \mathrm{CI}_{95}$ $=68.5-78.4$ ). Latent toxoplasmosis had no effect on the risk of lowering calcidiol levels in blood serum under the lower reference value. The results of logistic regression were non-significant both in men $(\mathrm{P}=0.54, \mathrm{OR}=0.83$ $\left.\mathrm{CI}_{95}=0.46-1.51\right)$ and in women $(\mathrm{P}=0.67, \mathrm{OR}=1.13$, $\left.\mathrm{CI}_{95}=0.65-1.98\right)$.

\section{Study C. A cross-sectional study performed on representatives of the general population}

We obtained data from 11 Toxoplasma-positive and 76 Toxoplasma-negative men and 18 Toxoplasma-positive and 86 Toxoplasma-negative women. The average age was 32 years $(\mathrm{SD}=9.05)$ in men and 27.4 years $(\mathrm{SD}=7.53)$ in women. Again, the results of ANCOVA showed no significant influence of latent toxoplasmosis on calcidiol levels in either men $\left(\mathrm{F}_{1,84}=0.32, \mathrm{P}=0.58\right.$, eta $\left.{ }^{2}=0.004\right)$ or women $\left(\mathrm{F}_{1,101}=2.26, \mathrm{P}=0.14\right.$, eta $\left.^{2}=0.02\right)$ (see Fig. 1C). Calcidiol levels were similar in 11 Toxoplasmapositive $\left(\right.$ mean $\left.=73.4 \mathrm{nmol} / \mathrm{l} ; \mathrm{CI}_{95}=54.6-92.1\right)$ and 76 Toxoplasma-negative men (mean $=69.4 \mathrm{nmol} / \mathrm{l}$; $\left.\mathrm{CI}_{95}=64.7-74.2\right)$ as well as in 18 Toxoplasma-positive (mean $\left.=82.3 \mathrm{nmol} / 1 ; \mathrm{CI}_{95}=72.1-92.6\right)$ and 86 Toxoplasma negative women $\left(\right.$ mean $\left.=73.4 \mathrm{nmol} / 1 ; \mathrm{CI}_{95}=68.7-78.1\right)$. The age had a non-significant effect in this model both in men $\left(\mathrm{P}=0.26\right.$ eta $\left.^{2}=0.02\right)$ and in women $\left(\mathrm{P}=0.89\right.$, eta ${ }^{2}$ $<0.01)$. In men, the results of a logistic regression were non-significant $\left(\mathrm{P}=0.15, \mathrm{OR}=0.39, \mathrm{CI}_{95}=0.10-1.43\right)$. In women, however, the analogical results were close to the formal level of significance $(\mathrm{P}=0.05, \mathrm{OR}=0.33$, $\mathrm{CI}_{95}=0.11-1.02$ ), indicating that Toxoplasma-negative women are more likely to have calcidiol levels above the reference value of $75 \mathrm{nmol} / \mathrm{l}$.

\section{Meta-analyses}

The results of meta-analyses, comprising of all three studies are presented in the forest plot (Fig. 2). The heterogeneity was not significant $\left(\mathrm{P}=0.46, \mathrm{I}^{2}=0 \%\right)$.

\section{DISCUSSION}

The results of the first study performed on neurasthenic patients suggested a possible negative association between latent toxoplasmosis and vitamin D levels in blood serum. The two other studies, however, including the preregistered case-control study, showed a weak (formally non-significant) positive association between latent toxoplasmosis and the concentration of vitamin D. Taken together, results of these three studies do not support the proposed hypothesis that toxoplasmosis-associated decrease in vitamin D levels could play a role in the observed association between toxoplasmosis and mental and physical disorders and diseases. Although the sample size was large, Toxoplasma-positive samples were limited. It is therefore difficult to come to any significant conclusion and the results presented here are just preliminary. 
In contrast to our results, two recent studies (Kashan et al. 2019, Tayeb et al. 2019) suggested a significant association between toxoplasmosis and vitamin D deficiency. However, one study (Tayeb et al. 2019) was conducted on a specific population sample, on women who had a bad obstetric history $(\mathrm{BOH})$ and bone disorders. Also, Kashan et. al. (2019) showed a significant difference in the prevalence of $T$. gondii infection in two groups of vitamin D sufficient and deficient individuals in a case-control study on 70 participants. The main limitation of their research was a relatively small sample. On the other hand, Kahan et al. (2019) excluded people taking vitamin D supplements in the last three months and patients with chronic diseases from this study.

We did not use similar exclusion criteria. Consequently, we can speculate whether Study B participants on subfertile subjects take more vitamin supplements, including vitamin $\mathrm{D}$, due to a suspected fertility problem. Similarly, participants who volunteered in Study C could be more interested in their health and also used more dietary supplements.

Recent studies showed that latent toxoplasmosis has a wide range of adverse effects on the health of most individuals in the general population (Flegr et al. 2014b, Flegr and Escudero 2016). In Study C, Toxoplasma-infected subjects enjoyed significantly better health than those who were Toxoplasma-free (discussed in another study - Flegr et al. 2020 - performed on the same population of volunteers). Toxoplasma-positive people may use more vitamins due to their initially worse health condition. This could be the reason why we observed no association between vitamin D levels and latent toxoplasmosis.

It is known that vitamin D levels are affected by numerous internal and external factors (Tsiaras and Weinstock 2011). It is therefore possible that Toxoplasma infection does indeed decrease vitamin D levels, but people with higher pre-existing vitamin $\mathrm{D}$ levels are a priori more likely to become infected. Toxoplasmosis is, after all, more prevalent among inhabitants of smaller towns and villages (Kolbeková et al. 2007), whereby risk factors for toxoplasmosis include activities such as gardening (Frenkel et al. 1995, Tenter et al. 2000) and rabbit breeding (Kolbeková et al. 2007). At the same time, rural lifestyle is associated with more time spent outside, in sunlight, i.e., with activities that could lead to higher vitamin D levels.

The great benefit of this study is that it has been done on three independent samples. However, each of presented three studies had its specific limitations. Study A was performed on a very small sample of just 64 women and 8 men. The main limitation of study B was an atypical population (subfertile subjects) and the fact that serum samples were collected at different times of the year. In the Czech
Republic, the mean concentration of vitamin D fluctuates widely between winter and summer and resulting variability in the output variable would make it difficult to detect any possible effect of toxoplasmosis. The main limitation of study C was low prevalence of toxoplasmosis as well as a relatively small sample size, whereby the low number of Toxoplasma-infected subjects, just 11 men and 18 women, increased the risk of Type II error. It should be noted, however, that while the limited number of participants (in study C) and high variance of calcidiol concentrations could account for the absence of a significant effect, it cannot account for the opposite direction of the observed non-significant effect, namely higher calcidiol levels in Toxoplasma-infected subjects.

Except for study A, the two other studies were performed on representatives of healthy population. It is thus possible that toxoplasmosis indeed causes a decrease in vitamin D concentrations (which could trigger mental or physical disorders) only in a certain fraction of population, for instance in subjects with particular genetic or other predispositions.

In contrast to our prior expectations, vitamin D concentrations were almost the same in Toxoplasma-infected subjects (and in two populations even non-significantly higher) than in Toxoplasma-free subjects. These results contradict the hypothesis regarding a link between vitamin D levels and various mental and physical disorders. It should, nevertheless, be noted that this study was only looking at the link between toxoplasmosis and vitamin $\mathrm{D}$ level, not the association between toxoplasmosis and certain psychiatric and physical disorders. With the exception of study A, which showed a non-significantly lower level of vitamin D in infected subjects with various mental health problems, the two other studies were performed on representatives of a healthy population. We could hypothesise, for example, that toxoplasmosis leads to a decrease in vitamin D concentrations, which in turn increases the risk of mental or physical disorders but only in a predisposed fraction of the population. Studies B and C, however, did not include subjects with physical or mental health disorders. To test this modified version of the vitamin D hypothesis in future, vitamin D levels should be compared between, for instance, Toxoplasma-infected and Toxoplasma-free patients with schizophrenia, cancer or diabetes.

Acknowledgment. This work was supported by the Czech Science Foundation (grant No. 18-13692S), Charles University (Research Centre program No. 204056) and the Grant Agency of the Charles University in Prague (grant No. 104218). The authors would like to sincerely thank Jaroslav Novotný, Priessnitz Therapeutic Spa, Jeseník for his help with the study A and Anna Pilátová for her useful comments and help with preparing the final version of the article. 


\section{REFERENCES}

Abbas S., Linseisen J., Slanger T., Kropp S., Mutschelknauss E., Flesch-Janys D., Chang-Claude J. 2008: Serum 25-hydroxyvitamin D and risk of post-menopausal breast cancer - results of a large case-control study. Carcinogenesis 29: 93-99.

Ali A., Cui X., Eyles D. 2018: Developmental vitamin D deficiency and autism: putative pathogenic mechanisms. J. Steroid Biochem. Mol. Biol. 175: 108-118.

ANDERSON P.H. 2017: Vitamin D activity and metabolism in bone. Curr. Osteoporos. Rep. 15: 443-449.

Arling T., Yolken R., Lapidus M., Langenberg P., Dickerson F., Zimmerman S., Balis T., Cabassa J., Scrandis D., Tonelli L., Postolache T. 2009: Toxoplasma gondii antibody titers and history of suicide attempts in patients with recurrent mood disorders. J. Nerv. Ment. Dis. 197: 905-908.

Babu P., Nagendra K., Navaz R., Ravindranath H. 2007: Congenital toxoplasmosis presenting as hypogonadotropic hypogonadism. Ind. J. Pediatr. 74: 577-579.

Bin-Abbas B., Jabari M., Issa S., Al-Fares A., Al-Muhsen S. 2011: Vitamin D levels in Saudi children with type 1 diabetes. Saudi Med. J. 32: 589-592.

Bizzaro G., Antico A., Fortunato A., Bizzaro N. 2017: Vitamin $\mathrm{D}$ and autoimmune diseases: is vitamin $\mathrm{D}$ receptor (VDR) polymorphism the culprit? Isr. Med. Assoc. J. 19: 438-443.

Bresnahan M., Susser E., Schaefer C., Brown A., Sohler N., BEGG M. 2007: Race and schizophrenia in a U.S. birth cohort. Schizophr. Bull. 33: 228-228.

Cantor-Graae E., Selten J. 2005: Schizophrenia and migration: a meta-analysis and review. Am. J. Psychiatry 162: 12-24.

Da Silva R.C., Langoni H. 2009: Toxoplasma gondii: host-parasite interaction and behavior manipulation. Parasitol. Res. 105: 893-898

Datta P., Philipsen P.A., Olsen P., Bogh M.K., Johansen P., Schmedes A.V., Morling N., Wulf H.C. 2017: The half-life of 25(OH)D after UVB exposure depends on gender and vitamin $\mathrm{D}$ receptor polymorphism but mainly on the start level. Photochem. Photobiol. Sci. 16: 985-995.

Davis J., Eyre H., Jacka F., Dodd S., Dean O., McEwen S., Debnath M., McGrath J., Maes M., Amminger P., McGorRY P., Pantelis C., Berk M. 2016: A review of vulnerability and risks for schizophrenia: beyond the two hit hypothesis. Neurosci. Biobehav. Rev. 65: 185-194.

Enko D., Fridrich L., Rezanka E., Stolba R., Ernst J., Wendler I., Fabian D., Hauptlorenz S., Halwachs-BauMANN G. 2014: 25-Hydroxy-vitamin D status: limitations in comparison and clinical interpretation of serum-levels across different assay methods. Clin. Lab. 60: 1541-1550.

Eyles D., Burne T., McGrath J. 2013: Vitamin D, effects on brain development, adult brain function and the links between low levels of vitamin D and neuropsychiatric disease. Front Neuroendocrinol. 34: 47-64.

Ferder M., Inserra F., Manucha W., Ferder L. 2013: The world pandemic of vitamin D deficiency could possibly be explained by cellular inflammatory response activity induced by the renin-angiotensin system. Am. J. Physiol. Cell Physiol. 304: C1027-C1039.

Feskanich D., Ma J., Fuchs C., Kirkner G., Hankinson S. Hollis B., Giovannucci E. 2004: Plasma vitamin D metabolites and risk of colorectal cancer in women. Cancer Epidemiol Biomarkers Prev. 13: 1502-1508.

FLEGR J. 2015a: Neurological and neuropsychiatric consequences of chronic Toxoplasma infection. Curr. Clin. Microbiol. Rep. 2: $163-172$.

FleGR J. 2015b: Schizophrenia and Toxoplasma gondii: an undervalued association? Expert Rev. Anti-Infect. Ther. 13: 817-820.
FLEGR J., ESCUDERO D. 2016: Impaired health status and increased incidence of diseases in Toxoplasma-seropositive subjects - an explorative cross-sectional study. Parasitology 143: 1974-1989.

FleGR J., HoráČEK J. 2018: Toxoplasmosis, but not borreliosis, is associated with psychiatric disorders and symptoms. Schizophr. Res. 197: 603-604.

Flegr J., Klapilová K., KañKovÁ Š. 2014a: Toxoplasmosis can be a sexually transmitted infection with serious clinical consequences. Not all routes of infection are created equal. Med. Hypotheses 83: 286-289.

Flegr J., Prandota J., SovičKová M., Israili Z. 2014b: Toxoplasmosis - a global threat. Correlation of latent toxoplasmosis with specific disease burden in a set of 88 countries. PLoS ONE 9: e90203

Flegr J., Příplatová L., Hampl R., Bičíková M., Řípová D., MoHR P. 2014c: Difference of neuro- and immunomodulatory steroids and selected hormone and lipid concentrations between Toxoplasma-free and Toxoplasma-infected but not CMV-free and $\mathrm{CMV}$-infected schizophrenia patients. Neuroendocrinol. Lett. 35: 20-27.

Flegr J., Sýkorová K., Fiala V., Hlaváčová J., Bičíková M., Máčová L., KaŇKOVÁ Š. 2020: Increased 25(OH)D3 level in redheaded people: could redheadedness be an adaptation to temperate climate? Exp. Dermatol. 29: 598-609.

Frenkel J., Hassanein K., Hassanein R., Brown E., ThulLiez P., Quinteronunez R. 1995: Transmission of Toxoplasma gongii in Panama City, Panama: a 5-year prospective cohort study of children, cats, rodents, birds, and soil. Am. J. Trop. Med. Hyg. 53: 458-468.

Garland C., Gorham E., Mohr S., Garland F. 2009: Vitamin D for cancer prevention: global perspective. Ann. Epidemiol. 19: 468-483.

Ghaffarifar F., Pour M., Sharifi Z., Asl A., Al-Kawaz E. 2010: The effect of vitamin D3 Alone and mixed with IFN-gamma on tachyzoites of Toxoplasma gondii (RH strain) proliferation and nitric oxide (NO) production in infected macrophages of BALB/C mice. Iran. J. Parasitol. 5: 48-56.

HAdDAD J.G., Hahn T.J. 1973: Natural and synthetic sources of circulating 25-hydroxyvitamin D in man. Nature 244: 515-517.

Hlaváčová J., Flegr J., Řežábek K., Calda P., Kaňková Š. 2021: Male-to-female presumed transmission of toxoplasmosis between sexual partners. Am. J. Epidemiol. In press. https://doi. org/10.1093/aje/kwaa198

Hsu P., Groer M., Beckie T. 2014: New findings: depression, suicide, and Toxoplasma gondii infection. J. Am. Assoc. Nurse Pract. 26: 629-637.

Chakhtoura M., Azar S. 2013: The role of vitamin D deficiency in the incidence, progression, and complications of type 1 diabetes mellitus. Int. J. Endocrinol. 148673.

Institute of Medicine (US) Standing Committee on the Scientific Evaluation of Dietary Reference Intakes. 1997: Dietary reference intakes for calcium, phosphorus, magnesium, vitamin D, and fluoride. Washington, D.C.: National Academies Press.

KaňKová Š., Flegr J., Calda P. 2015a: An elevated blood glucose level and increased incidence of gestational diabetes mellitus in pregnant women with latent toxoplasmosis. Folia Parasitol. 62: 056 .

KaňKová Š., Flegr J., CAlda P. 2015b: The influence of latent toxoplasmosis on women's reproductive function: four cross-sectional studies. Folia Parasitol. 62: 041.

KaŇKová Š., HlaváČová J., Flegr J. 2020: Oral sex: a new, and possibly the most dangerous, route of toxoplasmosis transmission. Med. Hypotheses 141: 5. 
Kashan Z., Shojaee S., Keshavarz H., Arbabi M., Delavari M., Salimi M. 2019: Vitamin D deficiency and Toxoplasma infection. Iran. J. Publ. Hlth 48: 1184-1186.

Kodym P., Machala L., Roháčová H., Širocká B., Malý M. 2007: Evaluation of a commercial IgE ELISA in comparison with IgA and IgM ELISAs, IgG avidity assay and complement fixation for the diagnosis of acute toxoplasmosis. Clin. Microbiol. Infect. 13: 40-47.

Kolbeková P., Kourbatová E., Novotná M., Kodym P., Flegr J. 2007: New and old risk-factors for Toxoplasma gondii infection: prospective cross-sectional study among military personnel in the Czech Republic. Clin. Microbiol. Infect. 13: 1012-1017.

Lavie C., DiNicolantonio J., Milani R., O'Keefe J. 2013: Vitamin D and cardiovascular health. Circulation 128: 2404-2406.

Lerchbaum E., Obermayer-Pietsch B. 2012: Vitamin D and fertility: a systematic review. Eur. J. Endocrinol. 166: 765-778.

Lund B., Sørensen O.H. 1979: Measurement of 25-hydroxyvitamin D in serum and its relation to sunshine, age and vitamin D intake in the Danish population. Scand. J. Clin. Lab. Invest. 39: $23-30$.

Markovitz A., Simanek A., Yolken R., Galea S., Koenen K., Chen S., Aiello A. 2015: Toxoplasma gondii and anxiety disorders in a community-based sample. Brain Behav. Immun. 43: 192-197.

de Oliveira C., Hirani V., Biddulph J. 2018: Associations between vitamin D levels and depressive symptoms in later life: evidence from the English longitudinal study of ageing (ELSA) J. Gerontol. A. Biol. Sci. Med. Sci. 73: 1377-1382.

Papadimitriou D.T. 2017: The big vitamin D mistake. J. Prev. Med. Publ. Hlth. 50: 278-281.

Pedersen M., Mortensen P., Norgaard-Pedersen B., PosTOLACHE T. 2012: Toxoplasma gondii infection and self-directed violence in mothers. Arch. Gen. Psychiatry 69: 1123-1130.

Ryan J.W., Anderson P.H., Turner A.G., Morris H.A. 2013: Vitamin D activities and metabolic bone disease. Clin. Chim. Acta 425: 148-152.
Schneider B., Weber B., Frensch A., Stein J., Fritze J. 2000: Vitamin D in schizophrenia, major depression and alcoholism. J. Neural Transm. 107: 839-842.

Sutterland A., Fond G., Kuin A., Koeter M., Lutter R., van Gool T., Yolken R., Szoke A., Leboyer M., de HaAn L. 2015: Beyond the association. Toxoplasma gondii in schizophrenia, bipolar disorder, and addiction: systematic review and meta-analysis. Acta Psychiatr. Scand. 132: 161-179.

Tayeb F., Salman Y., Ameen K. 2019: The impact of Toxoplasma gondii infection on the vitamin D3 levels among women in childbearing age in Kirkuk Province-Iraq. Open J. Med. Microbiol. 9: $151-167$.

Tenter A., Heckeroth A., Weiss L. 2000: Toxoplasma gondii: from animals to humans. Int. J. Parasitol. 30: 1217-1258.

Torrey E., Bartko J., Yolken R. 2012: Toxoplasma gondii and other risk factors for schizophrenia: an update. Schizophr. Bull. 38: 642-647.

Torrey E., Yolken R. 2003: Toxoplasma gondii and schizophrenia. Emerg. Infect. Dis. 9: 1375-1380.

Tsiaras W., Weinstock M. 2011: Factors influencing vitamin D status. Acta Derm. Venereol. 91: 115-124.

Tworoger S., Lee I., Buring J., Rosner B., Hollis B., HANKINSON S. 2007: Plasma 25-hydroxyvitamin D and 1,25-dihydroxyvitamin D and risk of incident ovarian cancer. Cancer Epidemiol. Biomarkers Prev. 16: 783-788.

Viechtbauer W. 2010: Conducting meta-analyses in R with the metafor Package. J. Stat. Softw. 36: 1-48.

Vierucci F., Del Pistoia M., Fanos M., Erba P., Saggese G. 2014: Prevalence of hypovitaminosis D and predictors of vitamin D status in Italian healthy adolescents. Ital. J. Pediatr. 40

Yuan Z., Gao S., Liu Q., Xia X., Liu X., Liu B., Hu R. 2007: Toxoplasma gondii antibodies in cancer patients. Cancer Lett. 254: 71-74.

Zhou Y.H., Lu Y.J., Wang R.B., Song L.M., Shi F., Gao Q.F., Luo Y.F., Gu X.F., WANG P. 2002: [Survey of infection of Toxoplasma gondii in infertile couples in Suzhou countryside]. Zhonghua Nan Ke Xue 8: 350-352. (In Chinese.)

Cite this article as: Kaňková Š., Bičíková M., Máčová L., Hlaváčová J., Sýkorová K., Jandová D., Flegr J. 2021: Latent toxoplasmosis and vitamin D concentration in humans: three observational studies. Folia Parasitol. 68: 005. 